\title{
Analisis Prosedur Perawatan Mesin Motorizer Sedimen di PDAM Tirta Pakuan Kota Bogor
}

\author{
Rio Nurman Gumilar, M. Tirtana Siregar* \\ Program Studi Manajemen Logistik, Fakultas Manajemen, Politeknik APP Jakarta \\ rionurmangumilar@gmail.com; tirtana.mts@gmail.com
}

\begin{abstract}
Abstrak -- Penelitian ini bertujuan untuk mengetahui penerapan prosedur, ketidaksesuaian proses kerja perawatan dan perbaikan mesin serta menganalisis penyebab kerusakan mesin motorizer pada PDAM Tirta Pakuan Kota Bogor. Data yang digunakan dalam penelitian ini adalah data primer dan sekunder. Data primer didapatkan melalui pengamatan dan wawancara kepada pihak-pihak terkait dibagian mekanikal dan elektrikal. Data sekunder berupa data SOP perawatan dan perbaikan mesin dari perusahaan. Metode deskriptif, kompratif, dan evaluatif digunakan untuk menganalisis kondisi aktual dan prosedur kerja perawatan dan perbaikan mesin serta membandingkan antara hasil yang didapat dari penelitian ini pada pelaksanaan dari proses kerja perawatan dan perbaikan mesin masih terdapat tahapan yang tidak dijalankan sesuai prosedur. Menggunakan metode Fishbone Diagram, jenis kerusakan yang paling dominan terjadi pada mesin motorizer adalah gulungan terbakar dengan tingkat kontribusi sebesar 53,125\%. Dengan menggunakan Pareto Diagram,analisis ini dapat memberikan informasi bagi perusahaan untuk lebih memperhatikan kegiatan perawatan dan perbaikan mesin agar kegiatan proses kerja di bagian mekanikal dan elektrikal berjalan dengan baik dan lancar.
\end{abstract}

Kata kunci: Mesin Motorizer; Perawatan Mesin; Standard Operating Procedure (SOP).

\begin{abstract}
This research have objective to determine the application of procedures, mismatches work processes and maintenance of machinery repair and analyze the causes of motor engine damage in the PDAM Tirta Pakuan Bogor City. The data used in this research are primary and secondary data. Primary data obtained through observations and interviews to the parties concerned in the mechanical and electrical parts. Secondary data in the form of data SOP maintenance and repair machine from company. Descriptive, comprative, and evaluative methods are used to analyze the actual condition and working procedures of maintenance and repair of machinery and to compare between the results obtained from this research on the implementation of the maintenance work process and the repair of machines there are still stages that are not executed according to the procedure. Using the Fishbone Diagram method, the most dominant type of damage occurring in the motorizer engine is a burning roll with a contribution rate of $53.125 \%$. Using Pareto Diagram, this analysis can provide information for the company to pay more attention to the maintenance and repair activities of the machine so that the work process activities in the mechanical and electrical section run well and smoothly.
\end{abstract}

Keywords: Machine Treatment; Motorizer Machine; Work Procedure

\section{PENDAHULUAN}

Air bersih merupakan hal penting bagi kehidupan manusia terutama untuk dikonsumsi sebagai air minum. Dalam proses pengolahan air bersih atau air minum dilakukan dua cara yaitu dengan pengolahan dan langsung dari sumbernya (mata air). Khusus untuk proses pengolahan air perlu dilakukan penyadapan air baku, penyaringan, prasedimentasi, penampungan air baku, pengukuran $\mathrm{pH}$ dan Ntu, pendosisan koagulan, koagulasi, flokulasi,

\begin{tabular}{lcl}
\hline Artikel masuk & $:$ & 04 November 2017 \\
Artikel direvisi & $:$ & 18 November 2017 \\
Artikel diterima & $:$ & 18 November 2017 \\
&
\end{tabular}

sedimentasi, aerasi, filtrasi, sampai air bersih atau air minum. Peralatan dan mesin-mesin diperlukan dalam pengolahan air untuk menghasilkan air bersih atau air minum yang sesuai standar. Mesin-mesin tersebut harus mendapatkan perawatan agar bekerja dengan baik dan hasilnya sesuai dengan standar.

Perawatan mesin merupakan kegiatan perbaikan, pemeliharaan , penggantian, pembersihan, penyetelan dan pemeriksaan objek yang menjadi objek perawatan (kurniawan, 2013). Kuntadi (2013) menyatakan perawatan mesin adalah kegiatan terencana untuk menjaga peralatan, mengadakan perbaikan agar keadaan 
proses produksi berjalan dengan baik dan mencegah kerusakan.

Perencanaan dan evaluasi terhadap sistem perawatan mempunyai tujuan menghindari breakdown tidak terencana dan menekan downtime (Hakim \& Fahrizal, 2014). Sistem perawatan ini mempunyai tujuan untuk memperpanjang usia pemakaian peralatan, mencapai biaya perawatan seminimal mungkin dan mendukung kemampuan mesin agar dapat memenuhi kebutuhan sesuai dengan fungsinya.

PDAM Tirta Pakuan Kota Bogor adalah Perusahaan Daerah Air Minum yang berperan khusus menyalurkan air bersih kepada seluruh kalangan masyarakat yang berada di Kota Bogor. PDAM Tirta Pakuan Kota Bogor melakukan proses produksi secara terus-menerus selama 24 jam, sehingga peran penting yang harus dilakukan adalah mengutamakan perawatan mesin yang menjadi kunci utama dalam produk air bersih yang harus diberikan kepada seluruh kalangan konsumen. Kegiatan pengecekan kondisi mesin dilakukan sesuai dengan jadwal yaitu 1 minggu sekali. Berbagai uraian aktivitas pengolahan air bersih yang dijalankan dan banyak mesin-mesin yang digunakan untuk mengolah air baku menjadi air bersih. Salah satunya mesin yang paling penting pada tahap sedimentasi adalah mesin motorizer.

Pada penelitian ini yang menjadi objeknya adalah mesin motorizer. Pada tahap sedimentasi mesin motorizer sangatlah penting karena berfungsi sebagai drain atau buang lumpur yang telah mengendap setelah terjadi proses flokulasi (pengadukan lambat). Jika mesin rusak maka lumpur yang biasanya dibuang ditahap sedimentasi akan tertahan di bawah, mengakibatkan flock akan naik ke atas, ketahap air bersih yang kemudian berpengaruh kepada Ntu (kekeruhan).

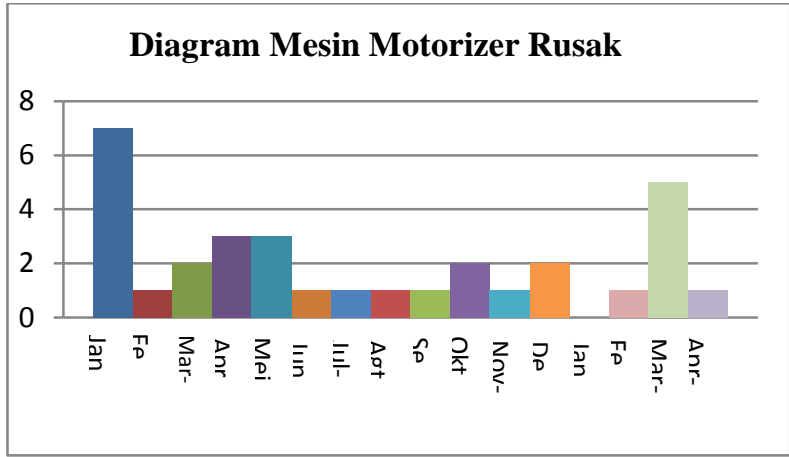

Gambar 1. Data Mekanikal dan Elektrikal Bulan Januari 2016 - April 2017

Sumber : Bagian Mekanikal dan Elektrikal PDAM Tirta Pakuan Kota Bogor 2017
Gambar 1 menunjukan kerusakankerusakan mesin motorizer yang ada di PDAM Tirta Pakuan Kota Bogor dari bulan Januari 2016 - April 2017 dan beberapa faktor komponen mesin yang rusak seperti gulungan, hitter, bearing dan kapasitor dikarenakan tidak dilakukannya pelaksanaan preventive maintenance yang terdapat diprosedur perawatan mesin. Perlunya perlakuan khusus dalam perawatan atau pemeliharaan yang sesuai dengan prosedur yang ada untuk dapat mempertahankan kekuatan mesin dalam jangka waktu yang panjang, sehingga dapat menghindari pengeluaran biaya yang besar terhadap kerusakan mesin dan menghindari terhambatnya proses produksi.

Preventive maintenance yang terencana akan menjamin tercapainya desain kehandalan dari peralatan/mesin (Alwi, 2016). Analisis Kegagalan merupakan salah satu langkah preventive maintenance dalam melakukan pemeriksaan kerusakan atau kegagalan sehingga dapat ditentukan penyebab kerusakan atau kegagalan tersebut (Setiawan \& Witantyo, 2016). Analisis kegagalan mempunyai tujuan untuk menghindari kerusakan yang sama di masa mendatang dan sebagai langkah awal penentuan waktu perawatan dilakukan.

Perencanaan penjadwalan pergantian spare part mesin slooting mampu meminimalkan biaya perawatan yang terjadi pada komponen bearing kecil, bearing besar dan V belt (Bachtiar, Leksananto, \& Helianty, 2015). Hariady (2014) dalam penelitiannya Pompa 53-101C WTU Sungai Gerong mendapatkan hasil bahwa vibrasi yang tinggi merupakan penyebab kerusakan komponen pompa yang dipicu oleh kavitasi dan korosi pada pompa yang menyebabkan unbalance rotor akibat terkelupasnya lapisan coating pada impeller dan terikutnya endapan lumpur pada suction pompa.

Penelitian ini lebih fokus membahas kegiatan maintenance dengan memilih satu mesin yaitu Mesin Motorizer Sedimen unit 3 dekeng 1 dan menganalisis perbandingan antara SOP (Standard Operating Procedure) perawatan dan perbaikan mesin dengan kinerja yang aktual untuk menentukan apakah adanya ketidaksesuaian serta melihat akar permasalahan dengan metode fishbone dan metode pareto. Penelitian ini bertujuan untuk mengevaluasi penerapan prosedur perawatan mesin, mengetahui faktor penyebab terjadinya ketidaksesuaian dengan menggunakan metode fishbone diagram dan mengetahui penyebab kerusakan mesin motorizer paling dominan menggunakan metode pareto diagram 


\section{METODE PENELITIAN}

Metode analisis yang digunakan adalah metode deskriptif kualitatif, komparatif dan evaluatif. Secara umum penelitian ini termasuk penelitian kualitatif yang didukung oleh data kuantitatif. Metode deskriptif ini mendeskripsikan, mencatat, analisis dan menginterpretasikan kondisi yang terjadi. Metode komparatif adalah metode yang bersifat membandingkan persamaan dan perbedaan dua atau lebih faktafakta objek yang diteliti berdasarkan kerangka pemikiran tertentu. Sedangkan metode evaluatif, mengevaluasi suatu objek apakah telah dilaksanakan sesuai dengan yang diharapkan. Mengingat penulis melakukan metode komparatif dan evaluatif pada prosedur kerja perawatan mesin, membandingkan kesesuaian data dengan Standard Operating Procedure (SOP) perawatan dan perbaikan mesin dengan kondisi pelaksanaan pada PDAM Tirta Pakuan Kota Bogor.

Analisa ini berguna untuk mengetahui proses kerja yang ada pada bagian Mekanikal dan Elektrikal di PDAM Tirta Pakuan Kota Bogor. Pada pemecahan masalah, penulis menggunakan metode analisis pareto dan analisis fishbone. Analisis pareto adalah salah satu analisis yang dapat digunakan untuk pengambilan keputusan yang menghasilkan efek keseluruhan yang signifikan. Diagram pareto dapat digunakan untuk mengetahui prosentase penyebab kejadian sehingga dapat digunakan sebagai pengambilan keputusan untuk memperbaikinya.

Analisis fishbone adalah salah satu analisis yang dapat digunakan untuk memecahkan masalah dalam prosedur perawatan mesin yang tidak sesuai. analisis fishbone digunakan untuk identifikasi, eksplorasi dan grafik yang menggambarkan penyebab terjadinya suatu permasalahan yang terjadi (Asmoko, 2013). Fungsi dasar diagram fishbone (tulang ikan)/Cause and Effect (sebab dan akibat) untuk mengidentifikasi dan mengorganisasi penyebab-penyebab yang mungkin timbul dari suatu efek spesifik dan kemudian memisahkan akar penyebabnya. Hasil dan analisisnya akan ada di bagian pembahasan. Setelah itu akan diberikan kesimpulan dari analisis yag telah dilakukan. Analisa yang digunakan oleh penulis adalah SOP Perawatan dan Perbaikan Mesin pada PDAM Tirta Pakuan Kota Bogor.

\section{HASIL DAN PEMBAHASAN}

Dalam proses kerja perawatan mesin ada beberapa tahapan yang harus dilakukan. Hal ini bertujuan untuk menciptakan alur proses kegiatan yang sesuai dengan prosedur yang diterapkan oleh perusahaan. Namun sering kali ada beberapa tahapan yang kurang diterapkan dalam pelaksanaan.

Perusahaan yang memiliki pemeliharaan yang baik menjamin bahwa fasilitas-fasilitas produksi akan dapat beroperasi secara baik. Hal ini tidak menutupi kemungkinan bahwa perusahaan memiliki standar manajemen yang baik dalam meningkatkan kualitas kinerjanya. Salah satu cara meningkatkan kinerja sebuah usaha adalah dengan menetapkan Standard Operating Procedure (SOP) pada setiap unit kerjanya.

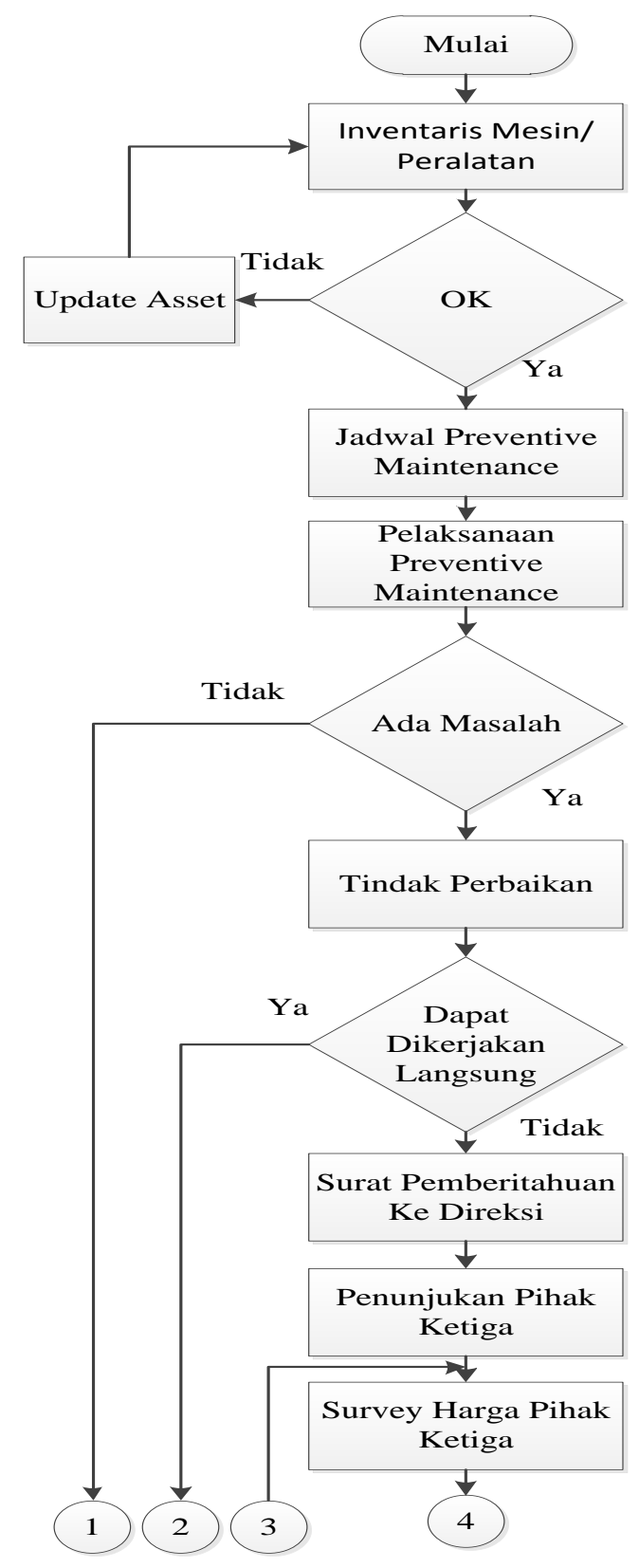




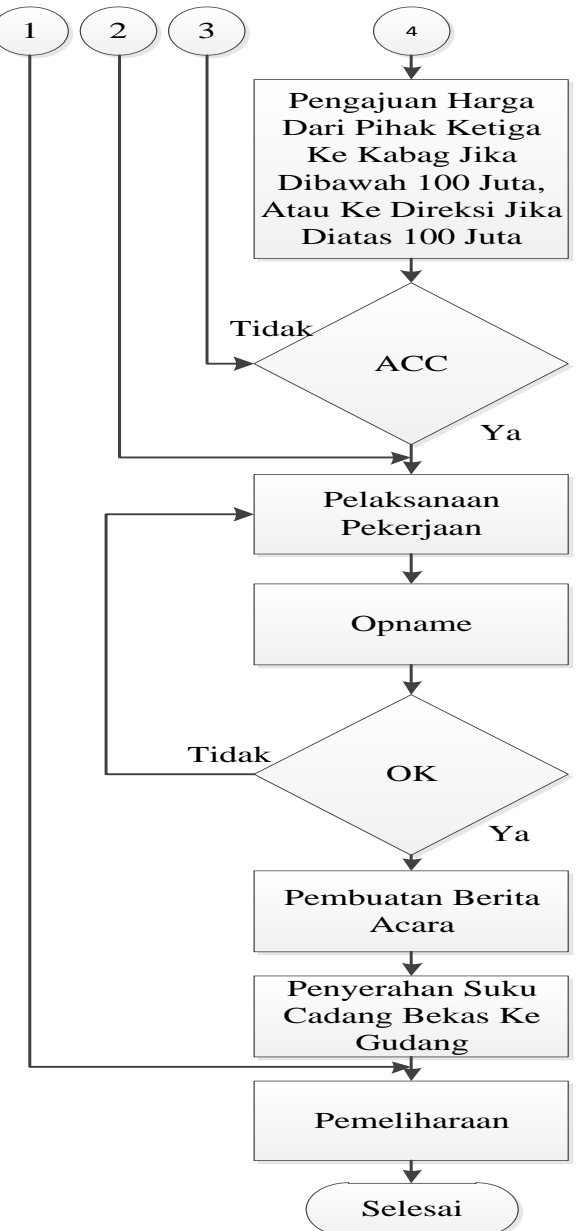

Gambar 2. Standard Operating Procedure (SOP) Perawatan Mesin

\section{Analisis Faktor Penyebab dan Dampak}

Terjadinya beberapa permasalahan dalam kegiatan perawatan mesin yang mengakibatkan terhambatnya produksi air yang dihasilkan dan tidak maksimal karena disebabkan oleh beberapa penyebab utama. Penyebab-penyebab utama inilah yanga akan dicari, dikaji, dan ditanggulangi sehingga masalah dapat terselesaikan hingga akarnya. Permasalahan akan di oleh menggunakan metode Fishbone Diagram dan Diagram Pareto untuk mendapatkan solusi yang terbaik bagi PDAM Tirta Pakuan Kota Bogor dalam kegiatan perawatan dan pemeliharaan mesin motorizer.

Permasalahan bahwa pihak Mekanikal dan Elektrikal tidak melakukan kegiatan pelaksanaan pemeliharaan preventive maintenance yang memberikan dampak negatif langsung pada produksi air. Mesin yang tidak dilakukan perawatan, pada akhirnya mengalami kerusakan pada bagian komponen mesin. Kegiatan pelaksanaan perawatan yang seharusnya dilakukan akan tetapi pada pelaksanaan tidak dilakukan, maka akan menimbulkan kerusakan dan akan menghambat kegiatan proses produksi pengolahan air, maka langkah yang harus dilakukan adalah mengidentifikasi faktor-faktor penyebab dan permasalahan jika pihak Mekanikal dan Elektrikal tidak melakukan Pelaksanaan preventive maintenance diolah menggunakan metode pareto diagram dan metode fishbone diagram.

Tabel 1 . Harga Kerusakan Komponen Mesin Motorizer Januari 2016 - April 2017

\begin{tabular}{|c|c|c|c|c|c|}
\hline No & $\begin{array}{c}\text { Komponen } \\
\text { Mesin }\end{array}$ & Harga satuan & $\begin{array}{l}\text { Dibutuhkan } \\
\text { dalam } \\
\text { Mesin }\end{array}$ & $\begin{array}{l}\text { Jumlah } \\
\text { Kerusakan } \\
\text { Pertahun }\end{array}$ & Kerugian perusahaan \\
\hline 1 & Gulungan & Rp 400.000,00 & 1 & 17 & Rp 6.800.000 \\
\hline 2 & Hitter & Rp 150.000,00 & 1 & 8 & Rp 1.200 .000 \\
\hline 3 & Bearing & $\mathrm{Rp} \quad 50.000,00$ & 5 & 4 & Rp 200.000 \\
\hline 4 & Kapasitor & Rp 100.000,00 & 1 & 3 & Rp 300.000 \\
\hline \multicolumn{2}{|c|}{ Total } & & 8 & 32 & Rp 8.500.000 \\
\hline
\end{tabular}

Berdasarkan tabel 1 di atas dapat diketahui total kerugian perusahaan akibat kerusakan mesin motorizer periode Januari 2016 - April 2017 akibat komponen mesin rusak adalah $\mathrm{Rp}$ 8.500.000. Kerugian perusahaan dapat diminimalkan dengan mengetahui penyebab-penyebab yang mengakibatkan kerusakan mesin tersebut. Dari diagram pareto Pareto pada gambar 3 di bawah yaitu jenis kerusakan yang terjadi pada mesin motorizer adalah gulungan terbakar $(53,125 \%)$, hitller mati (25\%), Bearing patah (12,5\%0 dan kapasitor mati sebesar $9,375 \%$. 


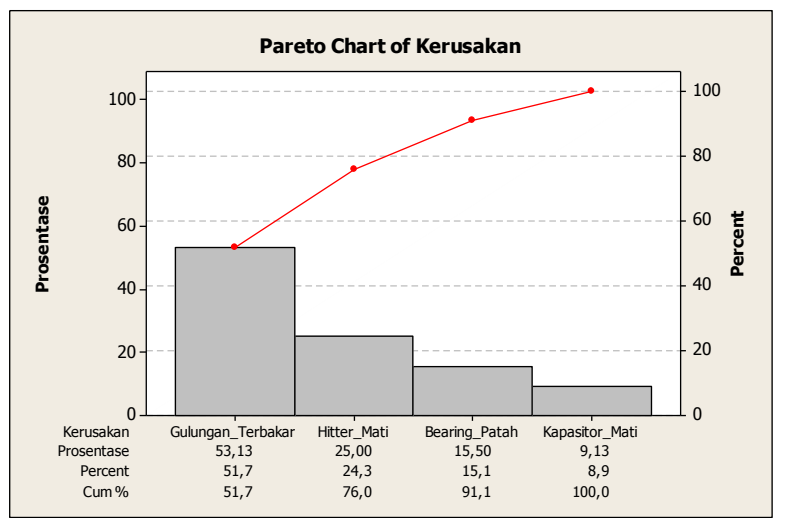

\section{Gambar 3. Diagram Pareto Jenis Kerusakan pada Mesin Motorizer}

Setelah diketahui persentase jenis kerusakan yang paling dominan terjadi pada mesin, langkah selanjutnya adalah dengan mengidentifikasi faktor-faktor penyebab permasalahan bahwa pihak Mekanikal dan Elektrikal tidak melakukan perawatan mesin sesuai jadwal dengan menggunakan metode sebab-akibat atau Fishbone Diagram.

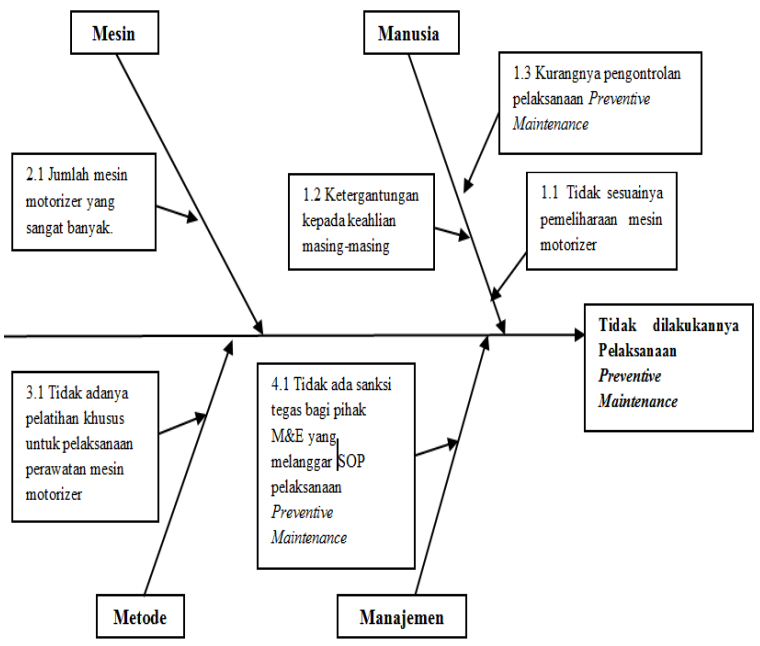

Gambar 4. Diagram Sebab-Akibat dari Tidak dilakukannya Pelaksanaan Preventive Maintenance

Dengan menggunakan bantuan alat berupa cause and effect diagram atau diagram sebab akibat, dapat diketahui penyebab dari ketidaksesuaian yang terjadi dari tidak dilakukannya jadwal preventive maintenance. Penyebab ketidaksesuaian tersebut terbagi atas empat faktor yaitu manusia, mesin, metode dan manajemen. Berikut penjelasan penyebab dari ketidaksesuaian yang terjadi dan didapatkan solusi dari keempat faktor diatas, yaitu sebagai berikut:

1. Faktor Manusia

Berdasarkan faktor manusia, terdapat tiga penyebab yang menyebabkan kesenjangan diantaranya:

a.Tidak sesuainya pemeliharaan mesin motorizer

Tidak sesuainya pelaksanaan preventive maintenance dengan aktual dikarenakan pihak mekanikal dan elektrikal tidak melakukan jadwal preventive maintenance yang seharusnya dilakukan 1 minggu sekali sesuai dengan jadwal yang telah di tentukan sehingga dapat meminimalisir kerusakan pada mesin terutama mesin motorizer. Jika pelaksanaan perawatan mesin dilakukan secara terjadwal, maka kerusakan yang terjadi lebih kecil dan biaya perbaikan yang dikeluarkan juga akan lebih sedikit.

b.Ketergantungan kepada keahlian masingmasing

Jumlah tenaga kerja Mekanikal dan Elektrikal sebanyak 7 orang, akan tetapi pihak Mekanikal dan Elektrikal masih tergantung kepada keahlian masing-masing terutama pada mesin motorizer yang hanya mengandalkan salah satu pegawai yang menguasai mesin tersebut.

c.Kurangnya pengontrolan pelaksanaan preventive maintenance

Kurangnya pengontrolan pelaksanaan preventive maintenance berpengaruh terhadap kinerja pelaksanaannya, yang seharusnya dilaksanakan jadi tidak dilaksanakan.

2. Faktor Mesin (Mesin sedimentasi motorizer)

Selama melakukan pengamatan, total mesin motorizer di inventaris yang berjumlah 91 unit tidaklah sesuai dengan perbandingan pegawai atau sumberdaya manusia di bagian Mekanikal dan Elektrikal yang berjumlah hanya tujuh orang. Hal ini menyebabkan tidak maksimalnya kegiatan preventive maintenance mesin motorizer, bahkan perawatan mesin motorizer tidak dilakukan.

3. Faktor Metode

Kurangnya pengetahuan akan pentingnya perawatan mesin khususnya mesin motorizer dan tidak adanya pelatihan khusus untuk prosedur kerja perawatan dan perbaikan mesin, berdampak terhadap mesin motorizer yang sering rusak dan hanya bisa digunakan secara manual. Pelatihan untuk prosedur perawatan dan perbaikan mesin motorizer di PDAM Tirta Pakuan Kota Bogor perlu dilakukan agar karyawan dapat 
memahami pentingnya manfaat, fungsi dan tanggungjawab agar mendapatkan umur komponen mesin yang lebih lama dan meghindari biaya yang timbul akibat kerusakan mesin.

4. Faktor Manajemen

Pihak manajemen tidak melakukan pengontrolan kinerja karyawan, tidak adanya sanksi tegas bagi pihak Mekanikal dan Elektrikal yang melanggar SOP (Standard Operating Procedure) pelaksanaan preventive maintenance, menyebabkan tidak dilaksanakannya perawatan mesin motorizer yang sudah terjadwalkan dalam prosedur perawatan mesin secara berkala

\section{KESIMPULAN}

BSecara umum kegiatan perawatan dan perbaikan mesin di PDAM Tirta Pakuan Kota Bogor sudah baik, karena PDAM Tirta Pakuan Kota Bogor sudah memiliki Standard Operational Procedure (SOP) terhadap kegiatan pemeliharaan dan perbaikan mesinnya. Namun, pada pelaksanaannya masih terdapat proses yang tidak dijalankan yaitu pada pelaksanaan Preventive Maintenance. Penyebab dari ketidaksesuaian disebabkan ketergantungan kepada keahlian masing-masing dan kurangnya pengontrolan pelaksanaan preventive maintenance, Mesin yang sangat banyak tidak sesuai dengan jumlah sumberdaya manusia, kurang pelatihan perawatan mesin motorizer. Jenis kerusakan yang paling dominan terjadi pada mesin motorizer adalah gulungan terbakar dengan tingkat kontribusi sebesar 53,125\%, dengan total kerugian sebesar Rp 6.800.000.

\section{DAFTAR PUSTAKA.}

Alwi, R. (2016). Reliability Centered Maintenance dalam Perawatan FO Service Pump Sistem Bahan Bakar Kapal Ikan. Jurnal Riset Teknologi Kelautan, 14(1), 77-86.

Asmoko, H. (2013). Teknik Ilustrasi MasalahFishbone Diagrams. Magelang: Badan Pendidikan Dan Pelatihan Keuangan Departemen Keuangan.

Bachtiar, D. P., Leksananto, K., \& Helianty, Y. (2015). Penjadwalan Perawatan Preventive pada Mesin Slotting DI CV. Cahaya Abadi Teknik. REKA INTEGRA, 3(4), 296-307.

Hakim, L., \& Fahrizal. (2014). Penerapan RCM pada Sistem Distribusi Air di PDAM Pasir Putih Pematangan Barangan Kabupaten Rokan Hulu. Jurnal Aptek, 4(2), 129-140.

Hariady, S. (2014). Analisa Kerusakan Pompa Sentrifugal 53-101C WTU Sungai Gerong PT. Pertamina RU III Plaju. Jurnal Desiminasi Teknologi, 2(1), 29-42.
Kuntadi, A. (2013). Perencanaan Sistem Perawatan Mesin Rotary Lobe Pump Melalui Reliability Centered Maintenance (RCM) (Studi Kasus PT. Lombok Gandaria). Jurusan Teknik Industri, Fakultas Teknik, Universitas Muhammadiyah Surakarta.

Kurniawan, F., (2013), Manajemen Perawatan Industri, Graha IImu, Yogyakarta

Setiawan, A., \& Witantyo, W. (2016). Analisa Kegagalan Poros Pompa Centrifugal Multistage (GA101A) Sub Unit Sintesa Urea PT. Petrokimia Gresik. Jurnal Teknik ITS, 5(2), 667-672. 